\title{
Acute stress hyporesponsive period in nestling Thin-billed prions Pachyptila belcheri
}

\author{
Petra Quillfeldt • Maud Poisbleau · Olivier Chastel · \\ Juan F. Masello
}

Received: 27 May 2008 / Revised: 15 October 2008 / Accepted: 20 October 2008 / Published online: 12 November 2008

(C) The Author(s) 2008. This article is published with open access at Springerlink.com

\begin{abstract}
When confronted with acute stressors, vertebrates show a highly conserved evolved sequence of physiological, hormonal and behavioural responses, including the activation of the hypothalamic-pituitary-adrenal axis. Many young vertebrates show a stress hyporesponsive period, where they exhibit a reduced glucocorticoid response. Here, we analyzed the stress response of nestling Thin-billed prions Pachyptila belcheri and compared chicks with different previous experience with capture and handling. We found that chicks had a stress response, but baseline and peak levels were below those measured in adults. The stress response of the chicks was rapid and followed by fast recovery, such that the total amount of corticosterone released in response to handling was very much lower in chicks than adults. These results indicate that nestling Thin-billed prions exhibit a stress hyporesponsive period. This was not due to habituation, as CORT measurements at baseline and elevated levels were similar in chicks handled daily and naïve chicks. The comparison with other published studies showed that the stress response of chicks usually peaks earlier and lower than in adults, and researchers should take care to measure stress-induced levels at an appropriate sampling time.
\end{abstract}

P. Quillfeldt $(\varangle) \cdot$ M. Poisbleau · J. F. Masello

Max-Planck-Institut für Ornithologie,

Vogelwarte Radolfzell, Schlossallee 2,

78315 Radolfzell, Germany

e-mail: petra.quillfeldt@gmx.de

O. Chastel

Centre d'Etudes Biologiques de Chizé,

Centre National de la Recherche Scientifique,

Villiers en Bois, 79360 Deux-Sèvres, France
Keywords Corticosterone $\cdot$ Handling · Procellariiformes · Stress hyporesponsive period $\cdot$ Stress response

\section{Introduction}

In adult birds, acute increases in glucocorticoids (GC) in response to unpredictable and noxious stimuli ("stressors" cf. Romero 2004), through activation of the hypothalamicpituitary-adrenal (HPA) axis, may increase fitness (e.g. Sapolsky et al. 2000), while chronic secretion can have deleterious consequences (e.g. Silverin 1986; Wingfield and Silverin 1986; Petitte and Etches 1991). Although numerous studies have investigated the HPA-axis activation in adult birds following the application of a standardized stressor (capture, handling and restraint, Wingfield 1994), relatively few studies have addressed this phenomenon in nestlings, even though such a trade-off may be even more severe in developing birds (Wada et al. 2007).

The main GC in birds, corticosterone (CORT) has been suggested to play a role in signalling hunger in nestling birds. In response to malnutrition, plasma GC are involved in stimulating chicks to beg harder and thus obtain more food (Kitaysky et al. 2001a, 2003; Goodship and Buchanan 2006; Quillfeldt et al. 2006). GC are also involved in the timing of predictable events and rhythms in the life of developing chicks, such as the day-night cycle (e.g. Quillfeldt et al. 2007c) and the transition to independence (Heath 1997; Schwabl 1999; Quillfeldt et al. 2007c). On the other hand, high levels of GC in nest-bound chicks of altricial species can be harmful because they are incapable of escaping from a perturbation and face potential longterm negative effects of elevated CORT. High levels of GC can affect the successful development, such as decreased growth (e.g. reptiles: Morici et al. 1997), compromised 
cognitive abilities (e.g. Kitaysky et al. 2003) and immune function (reviewed in McEwen et al. 1997). GC may also inhibit feather growth (Romero et al. 2005), such that growing chicks should be expected to have tight HPA-axis regulation compared to adults (e.g. Romero 2004; Walker et al. 2005; Wada et al. 2007).

Previous studies indicate the presence of a stress hyporesponsive period in young mammals (Sapolsky and Meaney 1986) and fish (Barry et al. 1995), i.e. a period of a reduction in the GC response to stress. In birds, studies on altricial or semialtricial chicks also indicate a dampened stress response during the nestling period (Redpolls Carduelis flammea: Romero et al. 1998, northern mockingbird Mimus polyglottos: Sims and Holberton 2000, white-crowned sparrow Zonotrichia leucophrys: Wada et al. 2007). In some species, adrenocortical response to handling increased gradually with age, reaching adult-like responses immediately before fledging (American kestrel Falco sparverius: Love et al. 2003; Magellanic penguin Spheniscus magellanicus: Walker et al. 2005). However, the data available so far are relatively sparse, and the presence and possible variability of a hyporesponsive period is not established in many bird families. In Procellariiformes, for example, the stress response of only one species has been studied recently (Adams et al. 2008). The Grey-faced petrel Pterodroma macroptera gouldi is a typical semi-precocial burrowbreeding bird, whose chicks that are unable to locomote and depend on their parents for food, although the chicks have well developed down and can thermoregulate soon after hatching. Grey-faced petrel chicks had high CORT responses to handling after $30 \mathrm{~min}$ of handling, from 2 to 4 days after hatching and throughout development.

In the present study, we measured plasma CORT in nestlings and adults of another burrow-breeding Procellariiform, the Thin-billed prion Pachyptila belcheri, after capture and restraint. We further test for effects of habituation, by comparing repeatedly handled chicks to naïve chicks. Thus, the aims of the present study were:

1. to compare the stress response between chicks of different ages and that of adults in order to establish whether nestling Thin-billed prions exhibit a stress hyporesponsive period,

2. to compare baseline levels and the stress response between regularly handled and naïve chicks, and

3. to test for influences of repeated handling on other parameters, in particular chick growth, body condition index and haematological parameters of condition (plasma triglycerides, proteins). Repeated handling (daily or twice daily) is needed for standard measurements of feeding rates and meal sizes in these small burrow-breeding petrels (e.g. Hamer et al. 2006; Quillfeldt et al. 2007a).

\section{Materials and methods}

Study site and study species

The study was carried out at New Island Nature Reserve, Falkland Islands, during the breeding seasons 2006-2007 and 2007-2008. The Thin-billed prion is a small and abundant subantarctic seabird, known to breed in two main areas: at Crozet and Kerguelen in the Southern Indian Ocean, and at the Falkland Islands (and possibly on some islands off Tierra del Fuego: Cox 1980; Clark et al. 1984) in the Southern Atlantic Ocean, New Island holding the largest known breeding population.

The life cycle and basic biology of Thin-billed prions have been described by Strange (1980). At New Island, recent studies explored variability in provisioning and parent-chick interactions (Quillfeldt et al. 2003, 2006; Quillfeldt et al. 2007a, b), as well as natural variability in CORT (Quillfeldt et al. 2007c). Thin-billed prions show the typical procellariiform pattern of a single-egg clutch and slow chick development, with an average fledging period of 50 days (Strange 1980). Thin-billed prions are burrow nesters, and we reached chicks in their nest chambers via short access tunnels in the roof of each burrow, capped with removable stone lids (e.g. Quillfeldt et al. 2003). This system facilitated rapid access to chicks, reducing overall disturbance. Marked nests were monitored for eggs and hatching chicks.

\section{Chick measurements}

The age of chicks in marked nests was determined to the nearest day, by calibrating wing length against wing growth in chicks of known age. Chicks of the study group (subsequently called "handled chicks") were weighed daily to the nearest $1 \mathrm{~g}$ using a digital balance. Wing length was measured every 3 days to the nearest $1 \mathrm{~mm}$ with a stopped wing rule, and tarsus length to the nearest $0.1 \mathrm{~mm}$ using callipers. When reaching a tarsus length of $30 \mathrm{~mm}$, chicks were ringed with Helgoland (Germany) steel rings to enable permanent identification. We calculated a body condition index using the observed body mass (m), relative to a multi-year mean mass for chicks of each age $\left(\mathrm{m}_{\text {mean }}\right)$, using the formula: $B C$ index $=\mathrm{m} / \mathrm{m}_{\text {mean }} \times 100$ (e.g. Quillfeldt et al. 2006). In species with a pattern of peak mass and mass recession, like Procellariiformes and Psittaciformes, body condition indices relative to age are more adequate than mass controlled for measures of body size. In these chicks, growth of structural size and body mass does not occur in a parallel fashion (e.g. approx. quadratic growth of mass, but logistic tarsus growth, with maximum tarsus often reached well before the end of the nestling stage; see also Masello and Quillfeldt 2002). Thus, mass versus 
structural size in chicks of these groups is not independent of chick age.

\section{Blood samples of handled chicks}

We collected blood samples of chicks handled daily and naïve chicks in 2007 and 2008 (sample sizes see Table 1). Blood samples $(0.2-0.4 \mathrm{ml})$ were collected during the day (09:30 to $16: 00$ hours) after capture by hand by puncture from the brachial vein in heparinised capillaries. Baseline samples were collected within 2 min from burrow opening to the end of blood sampling (e.g. Romero and Reed 2005). Baseline samples were taken when chicks reached 20 days $(n=49)$ and 40 days $(n=45)$ in 2007, and at 10-20 days in 2008 (due to the end of the fieldwork samples at 40 days of age could not be taken).

In addition, some handled chicks in 2007 were sampled after different times of constraint to measure the CORT during the stress response. We took one stress response sample per chick, either at 20 or 40 days of age, immediately following baseline sampling. To obtain stress response samples, one chick at a time was placed in a cloth bag, and left in its own burrow until the time of the sampling at 4, 8, 15, 25,35 or $45 \mathrm{~min}$ after capture (4 chicks for each handling time and age). During the respective waiting time, standard morphological measurements and weights were also taken, but took no longer than 2-3 min of handling time. The darkness in the bag per se may not be stressful for young birds that have spent their whole lives in a burrow. However, in addition to the stress of capture and handling, restraint in the bag changed the olfactory environment that is very important to adult and nestling prions (e.g. Bonadonna et al. 2003), such that we are confident that chicks perceived this period as stressful.

\section{Blood samples of naïve chicks}

In order to check for effects of repeated handling on chicks, we measured and sampled chicks in a number of nests in an area that had not previously been visited during the season. The measurements and sampling of these naïve chicks took place between 30 January and 7 February 2007 and between 19 and 23 January 2008. When we found a chick, it was blood sampled immediately and after $25 \mathrm{~min}$ in 2007 (after $15 \mathrm{~min}$ in 2008), ringed and measured as described for the handled chicks, and subsequently returned to their burrows. Chicks of the season 2008 were added as it had become apparent in our analysis of the data in 2007 that the initial sampling time of $25 \mathrm{~min}$ was later than the CORT peak during the chick stress response. Thus, we sampled naïve and handled chicks at 15 min after capture in 2008. The naïve chicks of 2007 had an estimated age (according to wing length) of 19 to 43 days (median 30 days) and the chicks in 2008 ranged between 14 and 23 days, thus including the same age range as the handled chicks (20 and 40 days in 2007, and 10-20 days in 2008). All naïve chicks were blood sampled only once.

\section{Adult samples}

Adults were sampled during the incubation period (October 2006). They were captured by hand on their nest and were sampled twice (within $2 \mathrm{~min}$ and after $25 \mathrm{~min}$ of restraint in a cloth bag). During the 25-min period, standard morphological measurements and weights were also taken, but took no longer than 2-3 min of handling time.

Sample storage, hormone and plasma biochemical analyses

Blood samples were immediately transferred to $0.5 \mathrm{ml}$ tubes, and kept on ice until centrifugation. Plasma was stored and transported frozen at $-20^{\circ} \mathrm{C}$.

Total CORT levels were assessed by radioimmunoassay at the Centre d'Etudes Biologiques de Chizé (CEBC) as detailed in Lormée et al. 2003. The samples of each year were run in one assay. The detection limit for CORT was $0.1 \mathrm{ng} / \mathrm{ml}$ and the lowest measurement was $0.3 \mathrm{ng} / \mathrm{ml}$. Intra-assay coefficients of variation were $4.05 \% \quad(n=12$ duplicates) for 2007 and 4.36\% ( $n=6$ duplicates) for 2008. Inter-assay coefficient of variations between both years was $5.22 \%$ ( $n=18$ duplicates). We chose two plasma biochemical parameters, representing a long-term and a short-term measure of condition: (1) Total plasma protein content is indicative of long-term nutritional state (e.g. Jenni-Eiermann
Table 1 Plasma corticosterone (CORT) baseline levels and stress-induced levels at 15 or 25 min after capture and restraint. The median, range and sample sizes are given, as well as the handling time for the stressinduced CORT levels

\begin{tabular}{|c|c|c|c|c|c|}
\hline $\begin{array}{l}\text { Breeding } \\
\text { season }\end{array}$ & Age group & Category & $\begin{array}{l}\text { Baseline CORT } \\
(\mathrm{ng} / \mathrm{ml})\end{array}$ & $\begin{array}{l}\text { Handling } \\
\text { time (min) }\end{array}$ & Elevated CORT $(\mathrm{ng} / \mathrm{ml})$ \\
\hline \multirow[t]{3}{*}{2007} & Chicks & Handled & $2.7(0.8-11.3), n=94$ & 25 & $11.4(1.0-44.2), n=8$ \\
\hline & & Naïve & $1.6(0.5-6.9), n=16$ & 25 & $15.6(2.2-46.7), n=17$ \\
\hline & Adults & Incubating & $5.5(1.0-19.0), n=78$ & 25 & $51.3(11.9-90.6), n=78$ \\
\hline \multirow[t]{2}{*}{2008} & Chicks & Handled & $3.2(1.2-12.0), n=26$ & 15 & $27.1(8.1-49.8), n=25$ \\
\hline & & Naïve & $2.7(0.9-4.4), n=12$ & 15 & $31.7(17.1-49.6), n=12$ \\
\hline
\end{tabular}


and Jenni 1996, Ots et al. 1998). Low serum protein levels $(<25 \mathrm{mg} / \mathrm{ml})$ may indicate chronic disease, stress or starvation (e.g. Lewandowski et al. 1986; Quillfeldt et al. 2004); (2) High triglyceride levels in blood indicate a resorptive nutritional state, during which dietary fat is deposited in adipose tissues (e.g. Jenni-Eiermann and Jenni 1998). In contrast, low triglyceride levels are symptomatic of a postresorptive, fasting state during which triglycerides from adipose tissues are hydrolyzed to free fatty acids and glycerol. Feeding rapidly leads to an increase in body mass and an increase in triglycerides (e.g. Jenni and Schwilch 2001; Masello and Quillfeldt 2004; Quillfeldt et al. 2004), thus providing a short-term measure of condition, indicating recent feeding.

Total plasma protein and triglyceride concentrations were determined for chicks of the season 2007 using standard spectrophotometric test combinations modified for small amounts of plasma (Thermo Scientific).

\section{Statistical analysis and data presentation}

Statistical tests were performed in SPSS 11.0 and SigmaStat 2.03. Normality was tested using Kolmogorov-Smirnov tests. All parameters except baseline CORT levels were normally distributed, and baseline CORT levels were normally distributed after $\ln$ transformation, and the assumptions of general linear models (normality, homoscedasticity, linearity) were then also met. We carried out General Linear Models using $\ln$ transformed CORT, and comparisons of CORT levels using non-parametric tests. For General Linear Models, we included partial Etasquared values $\left(\eta^{2}\right)$ as a measure of effect sizes (i.e. the proportion of the effect + error variance that is attributable to the effect). The sums of the partial Eta-squared values are not additive (e.g. http://web.uccs.edu/lbecker/SPSS/glm effectsize.htm). Means are given with standard errors.

\section{Results}

Stress response in regularly handled chicks

Chicks with regular handling experience had elevated CORT values in response to restraint in the cloth bag (Table 1, Fig. 1, GLM with CORT as dependent variable, and handling time and age group as factors, effect of handling time: $\left.F_{6,84}=14.4, P<0.001, \eta^{2}=0.506\right)$. There was no overall difference in plasma CORT between chicks of 20 and 40 days of age (GLM as before, effect of age: $F_{1,84}=1.6$, $\left.P=0.210, \eta^{2}=0.019\right)$. Neither baseline CORT $(0-2 \mathrm{~min})$ nor peak level $(8+15 \mathrm{~min})$ CORT differed between chicks at 20 and 40 days old (Mann-Whitney test, baseline: $U_{45,49}=1943, P=0.142$, peak: $\left.U_{8,8}=76, P=0.431\right)$.

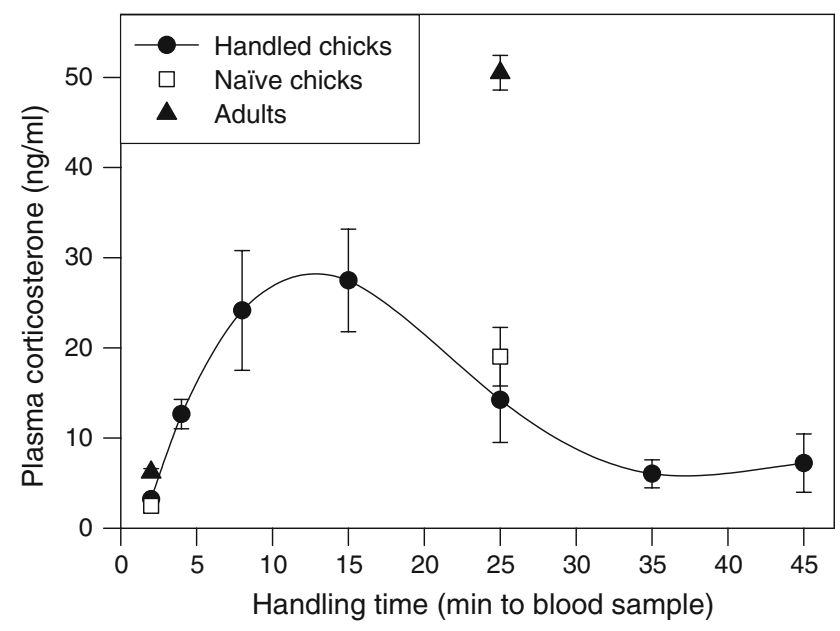

Fig. 1 Plasma corticosterone of adult and nestling Thin-billed prions during the breeding season 2007, after different times of handling and restraint. Error bars show mean and standard errors. Black dots are used for chicks with previous handling experience $(n=94$ for baseline samples, and $n=8$ for sampling times $4,8,15,25,35$ and $45 \mathrm{~min}$ ), white squares for previously unhandled chicks $(n=16$ for baseline samples, and $n=17$ for 25 min samples), and black triangles for adults ( $n=78$ for baseline and 25 min samples, respectively)

\section{Impact of daily handling}

Chick growth, measured as wing length versus date and body mass versus date, did not differ between handled and naïve chicks (Fig. 2). Naïve and daily handled chicks of the season 2007 did not differ in their body condition index $(t=1.4$, $d f=105, P=0.160$ ), baseline CORT values (Fig. 1, Table 1 , Mann-Whitney test: $\left.U_{16,94}=686, P=0.088\right)$ or plasma CORT sampled at $25 \mathrm{~min}$ handling time (Fig. 1, Table 1, Mann-Whitney $U_{8,17}=89, P=0.398$ ). Likewise, naïve and daily handled chicks of the season 2008 did not differ in their body condition index $(t=0.5, d f=36, P=0.639)$, baseline CORT values (Table 1 , Mann-Whitney test: $U_{12,26}=123$, $P=0.312$ ) or plasma CORT sampled at 15 min handling time (Table 1, Mann-Whitney $U_{12,25}=121, P=0.360$ ). Chicks with previous experience of handling did not differ from naïve chicks in parameters measured in baseline blood samples in 2007: plasma triglycerides (handled: $1070.4 \pm 129.3 \mathrm{mg} / \mathrm{dl}$, naïve: $1231.6 \pm 182.7 \mathrm{mg} / \mathrm{dl}$, MannWhitney test: $U_{12,35}=164, P=0.262$ ) and total plasma proteins (handled: $56.3 \pm 3.0 \mathrm{mg} / \mathrm{ml}$, naïve: $62.0 \pm 3.7 \mathrm{mg} / \mathrm{ml}$, Mann-Whitney test: $U_{12,35}=157, P=0.196$ ).

\section{Comparison with adult CORT levels}

Baseline CORT differed between adults and the two chick age groups in 2007 (Fig. 1, Table 1; Kruskal-Wallis ANOVA on Ranks: $H=47.6 d f=3, P<0.001$ ). Adults had higher baseline CORT values than each of the chick groups (Dunn's post hoc test, median $5.5 \mathrm{ng} / \mathrm{ml}$ for adults versus 

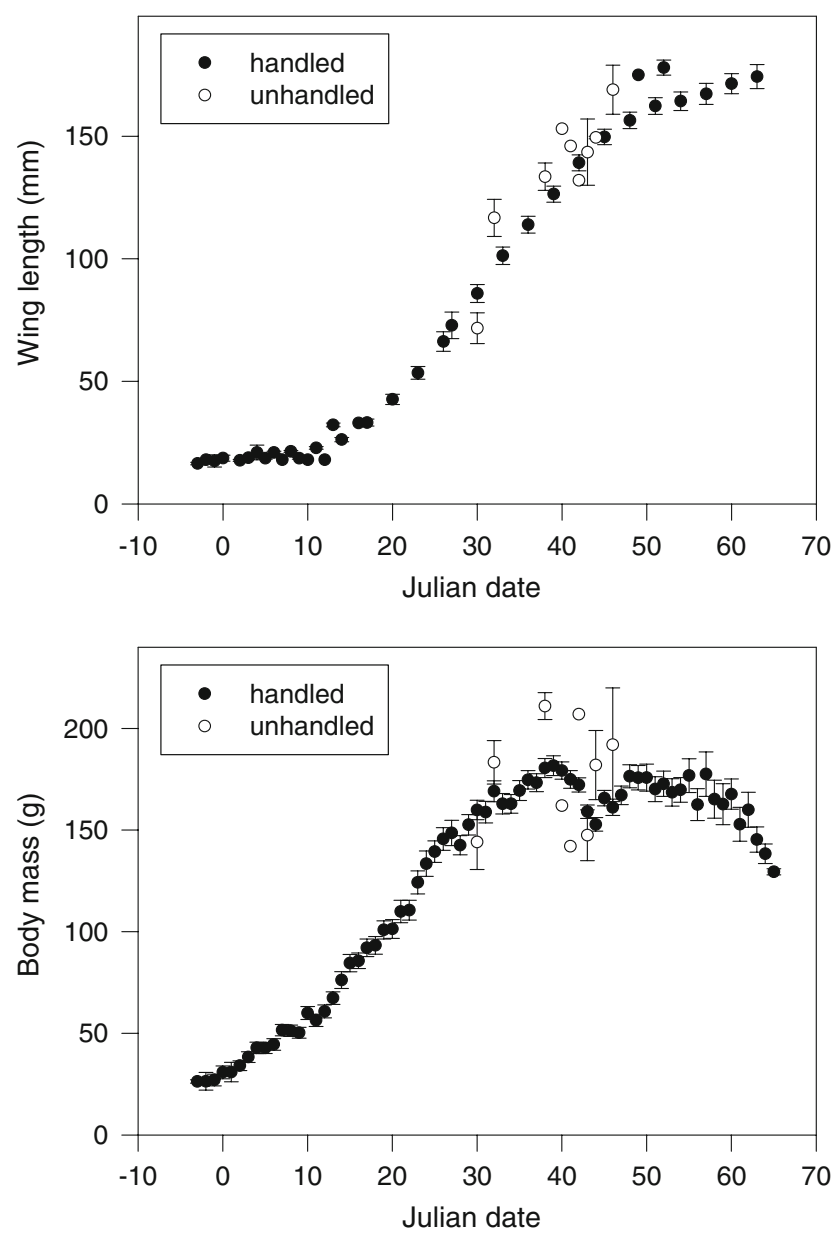

Fig. 2 Comparison of growth curves (mean \pm SE), relative to Julian date, of regularly handled chicks (black dots) and chicks from nests not previously checked (white dots)

$2.6 \mathrm{ng} / \mathrm{ml}$ for the oldest chicks). The CORT level at $25 \mathrm{~min}$ was much higher in adults than in chicks (Fig. 1, Table 1).

\section{Discussion}

Baseline and stress-induced concentrations of GCs have different physiological and behavioural effects, and thus can be thought of as reflecting two complementary hormonal systems (Romero 2004). This is caused by the presence of two receptor types, which respond at baseline and stressinduced GC levels, respectively. Thus, the study of stress responses is a complementary and important aspect to the study of the regulation of baseline GC levels.

Stress response

Like previous studies of altricial and semi-altricial birds (e.g. Kitaysky et al. 1999; Wada et al. 2007), we found that nestling Thin-billed prions could respond to restraint stress before fledging, however responses did not reach adult-like levels. The stress response of the chicks was rapid and followed by fast recovery, which, together with the lower 25 min CORT level in chicks, indicates that the total amount of GCs released in response to handling (the integrated response) was very much lower in chicks than in adults. This is consistent with the idea that the chicks of 3-6 weeks of age (1 week before fledging) were in a stress hyporesponsive period.

There is evidence that even during the stress hyporesponsive period, the stress response may be modulated by environmental factors. For example, food restriction in Black-legged kittiwake Rissa tridactyla and red-legged kittiwake $R$. brevirostris chicks led to enhanced stress response (Kitaysky et al. 1999, 2001b; Brewer et al. 2008). A stronger stress response was also found for parasiteinfested wild chicks (Kitaysky et al. 2001b), for newly hatched Magellanic Penguins visited by tourists (Walker et al. 2005), and for nestling Wilson's storm-petrels Oceanites oceanicus after mass loss due to a snow storm (Quillfeldt et al. 2004). Such exposure to high GC levels in early life may interfere with the development of the chicks. Therefore, a dampended stress response may be adaptive during the period when young chicks are increasing tissue mass and developing essential organs.

Thin-billed prions, like most birds, gain a large percentage of adult body mass during the first days or weeks of life. They reach adult mass, on average, at 3 weeks of age. Major developmental changes also occur rapidly, such as the development of endothermy, increased alertness and coordination of movements (e.g. Strange 1980).

The middle stage (3-6 weeks) of the nestling stage of Thin-billed prions is critical for development as well. During this period, chicks reach peak masses that may largely exceed that of the adults (a phenomenon known as nestling obesity, e.g. Hamer and Hill 1997). The tarsi (and possibly other bone structures) reach their final length during this stage, at about 30 days of age. In this period, the wing and tail feathers appear and grow at a flexible rate depending on the food availability (Quillfeldt et al. 2007a). As CORT has been found to inhibit feather growth (Romero et al. 2005), increased exposure to CORT in poorly fed chicks may adaptively down-regulate the rate of feather growth, and thus free resources for body maintenance.

The last week of the nestling development of Thinbilled prions is characterized by increased restlessness, especially in well-fed chicks. These chicks lose any excessive body mass, reach their final wing and tail lengths, and often leave their burrows during the night. They may be encountered in neighbouring burrows or at the surface. 
During this time, a large increase in baseline CORT has been observed (Quillfeldt et al. 2007c), which is consistent with these behavioural and developmental changes. We did not take stress response samples of chicks in this period close to fledging, but two studies suggest that in some species of birds the chicks close to fledging can also reach very high CORT peak values (Kitaysky et al. 2005), even in excess of that of adults (Love et al. 2003). Although the stress response was lower, in terms of total CORT production, than in adults, in relative terms it was comparable. Chicks showed a 10-fold increase in blood CORT levels and this degree of increase was equivalent to the levels seen in the adults, assuming that we measured the peak at $25 \mathrm{~min}$ (Table 1). More work remains to be done on the adult stress response in this species and to establish how these different levels act from the standpoint of CORT actions on glucocorticoid and mineralocorticoid receptors. The comparison between adult and chick responsiveness to acute stress has to be further investigated by incorporating the factors that modulate the biological action of CORT. Among them, corticosteroidbinding globulin (CBG) binds CORT in the plasma and regulates, therefore, the active unbound proportion of CORT, which is available for the tissues (Breuner and Orchinik 2002). Moreover, CBG may also enhance binding of CORT to the receptor and, therefore, affect the biological effect of increased CORT levels (Breuner and Orchinik 2002). Since our study indicates that nestling Thin-billed prions exhibit a stress hyporesponsive period, further investigation should include measurement of CBG capacity, which are known to increase over age in some passerine nestlings (Wada et al. 2007).

Implications for stress response sampling

Only few studies have sampled chicks at short intervals after capture. In almost all of these (Kitaysky et al. 1999, 2001b; Love et al. 2003; Brewer et al. 2008, this study, but see Wada et al. 2007), the peak CORT level was measured after ca. 10 min and thus, much earlier than in most adults. In the present study, chicks returned to levels close to baseline CORT after only $35 \mathrm{~min}$ (Fig. 1). A recent study on interannual variability in the stress response of kittiwake chicks (Brewer et al. 2008) indicated that environmental conditions may determine how long acute stress-induced peak levels of CORT are maintained: Although peak CORT values were reached after $10 \mathrm{~min}$ in all four years of study, they were maintained until $30 \mathrm{~min}$ after capture only in the two poorest years (Brewer et al. 2008). Thus, several studies that reported the first measurement of stress-induced levels at $30 \mathrm{~min}$ or later (e.g. Sims and Holberton 2000; Quillfeldt et al. 2004; Walker et al. 2005) may thus have missed the peak level, indicating that optimal sampling protocols for stress responses should be different for adults and chicks in many avian species. of kittiwake chicks quickly declined after.

Impact of research protocol

A major issue for scientists who conduct research on live animals is whether or not their research imposes significant stress on their study organisms. There is broad consensus about the need to minimize stress for any animals under study, as this is ethically indefensible (e.g. Association for the Study of Animal Behaviour/Animal Behavior Society 2003) and may also introduce confounding factors into the study.

Recent studies show that often, our evaluations of stressful methods, based on intuition, can be notoriously unreliable (e.g. Langkilde and Shine 2006), and suggest using the increase in GCs as a more objective marker of physiological stress in vertebrates (e.g. Romero 2004). Using this method, Langkilde and Shine (2006) compared different research procedures used commonly in lizards, and found that some superficially trivial manipulations such as housing the animal in an unfamiliar enclosure was very stressful for the animal, while a often criticized method (toeclipping) was less stressful than the technique frequently recommended to replace it on ethical grounds (microchip implantation).

We here attempted to measure the effects of our daily handling routine on the welfare of the chicks, by comparing parameters of growth and physiological condition between routinely handled chicks and chicks from nests outside the main study area, which had not been visited before. We found no difference in either chick growth, CORT measurements at baseline and elevated levels, agecorrected mass, plasma triglycerides or total plasma proteins. This is in line with studies on another nocturnally provisioning, burrow-nesting procellariiform seabird, the Short-tailed shearwater Puffinus tenuirostris (Saffer et al. 2000). In that study, chicks were subjected to three different levels of handling, but chick growth did not differ consistently between the three levels of disturbance. In addition to the parameters of growth, we here added physiological measures, and found no difference between routinely handled and naïve chicks, indicating no measurable harmful effects of the research routine on Thin-billed prion chicks.

Acknowledgments We are grateful to the New Island Conservation Trust for permission to work on the island and for providing accommodation and transport. We would like to thank Ian and María Strange for their excellent support of this work. This study was funded by a grant provided by the German Science Foundation DFG (Qu 148/1-ff).We thank André Lacroix, Colette Trouvé, Stéphanie Dano and Adeline 
Berger at the CEBC for their excellent technical assistance in corticosterone assays, and Simone Schroff and Gabi Schafheitle for assisting in protein and triglyceride assays. We are grateful for the constructive comments of two anonymous referees. The work was approved by the Falkland Islands Government (Environmental Planning Office).

Open Access This article is distributed under the terms of the Creative Commons Attribution Noncommercial License which permits any noncommercial use, distribution, and reproduction in any medium, provided the original author(s) and source are credited.

\section{References}

Adams NJ, Cockrem JF, Candy EJ, Taylor GA (2008) Non-precocial grey-faced petrel chicks (Pterodroma macroptera gouldi) show no age-related variation in corticosterone responses to capture and handling. Gen Comp Endocrinol 157:86-90

Association for the Study of Animal Behaviour/Animal Behavior Society (2003) Guidelines for the treatment of animals in behavioral research and teaching. Anim Behav 65:249-255

Barry TP, Malison JA, Held JA, Parrish JJ (1995) Ontogeny of the cortisol stress response in larval rainbow trout. Gen Comp Endocrinol 97:57-65

Bonadonna F, Hesters F, Jouventin P (2003) Scent of a nest: discrimination of own-nest odours in Antarctic prions, Pachyptila desolata. Behav Ecol Sociobiol 54:174-178

Breuner CW, Orchinik M (2002) Plasma binding proteins as mediators of corticosteroid action in vertebrates. J Endocrinol 175:99-112

Brewer JH, O'Reilly KM, Kildaw SD, Buck CL (2008) Interannual variation in the adrenal responsiveness of black-legged kittiwake chicks (Rissa tridactyla). Gen Comp Endocrinol 156:361-368

Clark GS, Goodwin AJ, von Meyer AP (1984) Extension of the known range of some seabirds on the coast of southern Chile. Notornis 31:321-324

Cox JB (1980) Some remarks on the breeding distribution and taxonomy of the prions (Procellariidae: Pachyptila). J South Aust Mus 18:91-121

Goodship NM, Buchanan KL (2006) Nestling testosterone is associated with begging behaviour and fledging success in the pied flycatcher, Ficedula hypoleuca. Proc R Soc London B 273:71-76

Hamer KC, Hill JK (1997) Nestling obesity and variability of food delivery in Manx Shearwater Puffinus puffinus. Funct Ecol 11:489-498

Hamer KC, Quillfeldt P, Masello JF, Fletcher K (2006) Sex differences in provisioning rules: responses of Manx shearwaters to supplementary chick-feeding. Behav Ecol 17:132-137

Heath J (1997) Corticosterone levels during nest departure of juvenile American kestrels. Condor 99:806-811

Jenni L, Schwilch R (2001) Plasma metabolite levels indicate change in body mass in reed warblers. Avian Sci 1:55-65

Jenni-Eiermann S, Jenni L (1996) Metabolic differences between the postbreeding, moulting and migratory periods in feeding and fasting passerine birds. Funct Ecol 10:62-72

Jenni-Eiermann S, Jenni L (1998) What can plasma metabolites tell us about the metabolism, physiological state and condition of individual birds? An overview. Biol Cons Fauna 102:312-319

Kitaysky AS, Piatt JF, Wingfield JC, Romano M (1999) The adrenocortical stress response of black-legged Kittiwake chicks in relation to dietary restrictions. J Comp Physiol B 169:303-310

Kitaysky AS, Wingfield JC, Piatt JF (2001a) Corticosterone facilitates begging and affects resource allocation in the black-legged kittiwake. Behav Ecol 12:619-625

Kitaysky AS, Kitaiskaia EV, Wingfield JC, Piatt JF (2001b) Dietary restriction causes chronic elevation of corticosterone and enhances stress response in red-legged kittiwake chicks. J Comp Physiol B 171:701-709

Kitaysky AS, Kitaiskaia EV, Piatt JF, Wingfield JC (2003) Benefits and costs of increased levels of corticosterone in seabird chicks. Horm Behav 43:140-149

Kitaysky AS, Romano MD, Piatt JF, Wingfield JC, Kikuchi M (2005) The adrenocortical response of tufted puffin chicks to nutritional deficits. Horm Behav 47:606-619

Langkilde T, Shine R (2006) How much stress do researchers inflict on their study animals? A case study using a scincid lizard, Eulamprus heatwolei. J Experim Biol 209:1035-1043

Lewandowski AH, Campbell TW, Harrison GJ (1986) Clinical chemistries. In: Harrison GJ, Harrison WR (eds) Clinical avian medicine and surgery. W.B. Saunders Company, Philadelphia, pp 192-200

Lormée H, Jouventin P, Trouve C, Chastel O (2003) Sex-specific patterns in baseline corticosterone and body condition changes in breeding red-footed Boobies Sula sula. Ibis 145:212-219

Love OP, Bird DM, Shutt LJ (2003) Corticosterone levels during postnatal development in captive American kestrels (Falco sparverius). Gen Comp Endocrinol 130:135-141

Masello JF, Quillfeldt P (2002) Chick growth and breeding success of the burrowing parrot. Condor 104:574-586

Masello JF, Quillfeldt P (2004) Are haematological parameters related to body condition, ornamentation and breeding success in wild burrowing parrots Cyanoliseus patagonus? J Avian Biol 35:445-454

McEwen BS, Biron CA, Brunson KW, Bulloch K, Chambers WH, Dhabhar FS, Goldfarb RH, Kitson RP, Miller AH, Spencer RL, Weiss JM (1997) The role of adrenocorticoids as modulators of immune function in health and disease: neural, endocrine and immune interactions. Brain Res Rev 23:79-133

Morici LA, Elsey RM, Lance VA (1997) Effects of long-term corticosterone implants on growth and immune functions in juvenile alligators, Alligator mississippiensis. J Exp Zool 279:156-162

Ots I, Murumägi A, Horak P (1998) Hematological health state indices of reproducing great tits: methodology and sources of natural variation. Funct Ecol 12:700-707

Petitte JN, Etches RJ (1991) Daily infusion of corticosterone and reproductive function in the domestic hen (Gallus domesticus). Gen Comp Endocrinol 83:97-405

Quillfeldt P, Masello JF, Strange IJ (2003) Breeding biology of the Thin-billed prion Pachyptila belcheri at New Island, Falkland Islands, in the poor season 2002/2003: Egg desertion, breeding success and chick provisioning. Polar Biol 26:746-752

Quillfeldt P, Masello JF, Möstl E (2004) Blood chemistry in relation to nutrition and ectoparasite load in Wilson's storm-petrels Oceanites oceanicus. Polar Biol 27:168-176

Quillfeldt P, Masello JF, Strange IJ, Buchanan KL (2006) Begging and provisioning of Thin-billed prions Pachyptila belcheri is related to testosterone and corticosterone. Anim Behav 71:1359-1369

Quillfeldt P, Strange IJ, Masello JF (2007a) Sea surface temperatures and behavioural buffering capacity in Thin-billed prions Pachyptila belcheri: breeding success, provisioning and chick begging. J Avian Biol 38:298-308

Quillfeldt P, Strange IJ, Segelbacher G, Masello JF (2007b) Male and female contributions to provisioning rates of Thin-billed prions Pachyptila belcheri in the South Atlantic. J Ornithol 148:367-372

Quillfeldt P, Poisbleau M, Chastel O, Masello JF (2007c) Corticosterone in Thin-billed prion Pachyptila belcheri chicks: diel rhythm, timing of fledging and nutritional stress. Naturwissenschaften 94:919-925

Romero LM (2004) Physiological stress in ecology: lessons from biomedical research. Trends Ecol Evol 19:249-255

Romero LM, Reed JM (2005) Collecting baseline corticosterone samples in the field: is under 3 min good enough? Comp Biochem Physiol A 140:73-79 
Romero LM, Soma KK, Wingfield JC (1998) The hypothalamus and adrenal regulate modulation of corticosterone release in redpolls (Carduelis flammea - an arctic-breeding song bird). Gen Comp Endocrinol 109:347-355

Romero LM, Strochlic D, Wingfield JC (2005) Corticosterone inhibits feather growth: potential mechanism explaining seasonal down regulation of corticosterone during molt. Comp Biochem Physiol A 142:65-73

Saffer VM, Bradley JS, Wooller RD, Meathrel CE (2000) The effect of human activity on the growth rates of short-tailed shearwater Puffinus tenuirostris chicks. Emu 100:49-53

Sapolsky RM, Meaney MJ (1986) Maturation of the adrenocortical stress response: neuroendocrine control mechanisms and the stress hyporesponsive period. Brain Res Rev 11:65-76

Sapolsky RM, Romero LM, Munck AU (2000) How do glucocorticoids influence stress response? Integrating permissive, suppressive, stimulatory, and preparative actions. Endocrinol Rev 21:55-89

Schwabl H (1999) Developmental changes and among-sibling variation of corticosterone levels in an altricial avian species. Gen Comp Endocrinol 116:403-408

Silverin B (1986) Corticosterone-binding proteins and behavioral effects of high plasma levels of hormones in a free-living population of pied flycatchers, Ficedula hypoleuca. Gen Comp Endocrinol 64:67-74

Sims CG, Holberton RL (2000) Development of the corticosterone stress response in young Northern Mockingbirds (Mimus polyglottos). Gen Comp Endocrinol 119:193-201

Strange IJ (1980) The Thin-billed prion, Pachyptila belcheri, at New Island, Falkland Islands. Gerfaut 70:411-445

Wada H, Hahn TP, Breuner CW (2007) Development of stress reactivity in white-crowned sparrow nestlings: total corticosterone response increases with age, while free corticosterone response remains low. Gen Comp Endocrinol 150:405-413

Walker BG, Boersma PD, Wingfield JC (2005) Physiological and behavioral differences in Magellanic Penguin chicks in undisturbed and tourist-visited locations of a colony. Conserv Biol 19:1571-1577

Wingfield JC (1994) Modulation of the adrenocortical response to stress in birds. In: Davey KG, Peter RE, Tobe SS (eds) Perspectives in comparative endocrinology. National Research Council of Canada, Ottawa, pp 520-528

Wingfield JC, Silverin B (1986) Effects of corticosterone on territorial behavior of free-living male song sparrows Melospiza melodia. Horm Behav 20:405-417 